\title{
Investigating the Effect of Visually/Textually Input-based Treatment on Evaluation and Potency Dimensions of Deep Vocabulary Knowledge by Iranian Intermediate EFL Learners
}

\author{
Ramin Vaezi \\ Islamic Azad University, Science and Research Branch, Tehran, Iran \\ E-mail: ramin2003@hotmail.com
}

\section{Doi:10.5901/mjss.2013.v4n2p89}

\section{Abstract:}

This study evaluates the potentially relative effectiveness of visual/textual input-based treatment on the acquisition of evaluation and potency dimensions of deep vocabulary knowledge by Iranian intermediate EFL learners. After administrating a CELT test and a general vocabulary knowledge test (for the intermediate) sixty participants out of one hundred from the intact intermediate classes. These sixty participants were randomly assigned to two groups: control and experimental each comprising of thirty participants. During the intervention, adjectives which describe the characteristics of people were highlighted (bolded or capitalized). In fact they were taught through visual/textual enhancement to the experimental group, whereas the students in the control group received no specific instruction. Later, the two groups took a posttest of awareness of evaluation and potency dimensions of deep vocabulary knowledge. The results indicated that visually/textually enhanced input teaching has a statistically significant influence on the awareness of evaluation and potency dimensions of deep vocabulary knowledge.

Keywords: Visual/Textual enhancement; Deep vocabulary knowledge; Affective dimension; Evaluation dimension; Potency dimension; Iranian EFL learners

\section{Introduction}

The field of second language acquisition (SLA) is witnessing an increasing interest in the idea that drawing learners' attention to the formal features of second language (L2) input is beneficial, and in some cases necessary, for optimal L2 development (Schmidt, 1990, 1993; Sharwood Smith, 1991, 1993). This interest has challenged researchers to develop pedagogic techniques that enhance input, and has resulted in a large body of research on visual/textual enhancement. The idea behind visual/textual enhancement is that by making formal aspects of L2 input more salient learners will be more likely to notice targeted forms, resulting in more intake, the subset of the input data that becomes available for further language processing.

During the past decades input has become even more important in the work of researchers using cognitive models to second/foreign language learning (Ellis, 1999; McLaughlin, 1987; Sharwood Smith, 1993, 1994; Tomasello, 1998). From a cognitive perspective, access to input is considered as perhaps the most important requirement for language development. It has been indicated that input provides essential positive evidence including the language data that allows acquisition to occur (Gass, 1997). A fundamental question in the field of SLA is to what extent and in what ways learners' attention should be drawn to certain forms. One of the methods of formal instruction which focuses on the concepts of noticing and consciousness-raising is the focus-on-form (FonF) approach.

In a FonF instructional approach, learners' attention will be attracted to certain forms. One of the implicit methods of FonF instruction is input-based instruction (Sharwood Smith, 1991), which aims at increasing the learners' noticing threshold by making the input salient and easily recognizable through manipulating different aspects of it (Sharwood Smith, 1993). Manipulation of input often takes the form of visual/textual input enhancement, in which the target forms become visually salient.

Moreover, vocabulary is a part of any language learning process. It would be impossible to learn a language without vocabulary. The important role that this component plays has been emphasized in all the different methods of language teaching. River (1981) states, "vocabulary cannot be taught. It can be presented, explained, included in all 
kinds of activities, but it must be learnt by individuals" (p.28). She further states that, "As language teachers, we must arouse interest in words, a certain excitement in personal development in this area" (p.29). She also suggests that language teachers must help their students by giving them ideas on how to learn vocabulary and some guidance on what to learn.

Vocabulary as a major component of language learning has been the object of numerous studies each of which has its own contribution to the field. Laufer (1997) considers vocabulary learning as the heart of language learning and language use. In fact, it is this vocabulary learning that makes the essence of any language. Without vocabulary, speakers cannot convey meaning and communicate with each other in any particular language.

As a teacher, the researchers have encountered with many students who have considerable vocabulary knowledge. They, however, fail to use them correctly in different domains. Learners, mainly, the upper intermediate and advanced ones, are often able to produce grammatically correct sentences. However, they produce very plain utterances which are unable to convey different emotional loads or to express shades of intensity of connotations.

It seems that this problem is due to the lack of deep vocabulary is an inseparable vocabulary knowledge and that the students' criterion in choosing words in context is surface structure and they fail to address the depth of vocabulary knowledge mainly evaluation and potency dimensions. Iranian EFL learners' poor deep vocabulary knowledge is a matter of concern among those involved in education and their quest for finding suitable remedies is getting more and more intense.

Having all said and done, the purpose of this study is to analyze the overall effectiveness of visual/textual inputbased instruction on the awareness of evaluation and potency dimensions of deep vocabulary knowledge by Iranian intermediate EFL learners.

According to Osgood, May, and Miron (1975), deep vocabulary knowledge involves evaluation, potency, and activity of vocabularies. The effect of visually enhanced input on the awareness of evaluation and potency dimension of deep vocabulary knowledge was the focus of this study with the following two research questions formulated:

1. Does visually/textually enhanced input have any statistically significant effect on Iranian intermediate EFL learners' awareness of evaluation dimension of vocabulary?

2. Does visually/textually enhanced input have any statistically significant effect on Iranian intermediate EFL learners' awareness of potency dimension of vocabulary?

\section{Literature Review}

\subsection{The Importance of Visual/Textual Enhancement}

Sharwood Smith (1991) contends that the most obvious way to try to affect subconscious processing beneficially is by making relevant target forms in the input salient. He further argues that making the input salient (input enhancement) has a highly positive effect on the rate and accuracy of L2 acquisition. Apparently, this salience does not involve directly manipulating the subconscious processes - this is by definition impossible - but it expands or restricts the information on which the processes may operate. On the importance of visual/textual enhancement Sharwood Smith $(1994$, p.181) writes the following lines:

"Whether the enhancement is subtle or very explicit, the learner's brain must still register it. What we know of learners includes the fact that they are very good at ignoring what appears to the outside observer to be very obvious... This is why we need to do a great deal of research on the matter to see what works best."

White (1998) has also stressed the importance of visual/textual enhancement. They have suggested that visual/textual enhancement can help L2 acquisition in two main ways: by drawing learners' attention to certain properties of $L 2$, and by helping them 'unlearn' their incorrect analyses of L2. Thus, visual/textual enhancement appears to affect learners' knowledge and performance in the second language, and it seems reasonable to expect language teachers and syllabus designers to make use of visual/textual enhancement.

\subsection{Visual/Textual Enhancement: Previous Studies}

Visual/Textual enhancement is an implicit and unobtrusive means to draw the learners' attention to linguistic forms contained in the written input. The basic method of enhancement is simply increasing the perceptual salience of the 
target forms via a variety of typographical techniques (e.g. highlighting, underlining, bolding, capitalizing, shadowing, color coding, etc.), which is also known as visual/textual enhancement.

Previous studies on the effects of input-based treatment-both those that used short-term treatments with rather limited exposure to the input (Alanen, 1995; Leow, 1993; Robinson, 1996; Shook, 1994; Williams, 1999), and those that adopted longer-term treatments with a greater amount of input exposure (Doughty, 1988, 1991; White, 1998)-produced quite mixed results. Three of these studies (Doughty, 1991; Shook, 1994; Williams, 1999) yielded positive findings for the facilitative effects of visual/textual enhancement, whereas four other studies (Alanen, 1995; Robinson, 1997; White, 1998) showed only limited effects. Finally, the other two studies (Doughty, 1988; Leow, 1993) found no significant effects at all. It should be mentioned, however, that various differences in these studies make direct comparison among them difficult.

In short, visual/textual input enhancement serves to draw the learners' attention to certain linguistic forms in the input that might otherwise go unnoticed or unlearned (Sharwood Smith, 1991). Sharwood Smith (1993) argues that visual/textual input enhancement contributes to the "input-to-intake" process because it highlights language forms that learners tend to ignore. This claim is also in line with the current theorizing in SLA that "noticing" is essential to L2 acquisition (Schmidt, 1990, 1995). It is, therefore, natural that input enhancement should have gained considerable popularity in the field of SLA.

\subsection{Evaluation and Potency Dimensions of Deep Vocabulary Knowledge}

Deep vocabulary knowledge involves how well a person knows a word, in contrast to breadth of vocabulary knowledge which involves how many words are known (Brown, 2007).

Evaluation dimension of vocabulary knowledge refers to how good or bad something is, that is, whether the entity has people's approval or disapproval in terms such as good vs. bad (Hiese 2002, p. 37). People may evaluate something as positive such as adjective "good" and they may evaluate something as negative such as adjective "bad".

Potency dimensions of deep vocabulary knowledge refers to an entity's impact in terms of being big versus little, powerful versus powerless, consequential versus immaterial (Heise 2002, p. 37). Potency shows the range of power or impact of an entity. "Powerful" is a potent adjective because it has the greatest impact, whereas "powerless" is nonpotent because it has the least impact.

\section{Research Methodology}

\subsection{Participants}

A total of 100 male students aged between 19 and 34 with Persian as their mother tongue were selected in this study from some language schools. In order to classify them in almost homogenized groups and screen the required number of subjects, they were given The Comprehensive English Language Test (CELT). Then, those who scored one standard deviation above and below the mean were selected for the main part of the study. So the total number of the subjects of this study was 60 . Furthermore, all the students participated in the research project voluntarily.

\subsection{Instruments}

\subsubsection{The Comprehensive English Language Test (CELT)}

In order to have a representative sample of the population under study a multiple-choice CELT was administered as the standard of the homogeneity of the learners. Having obtained the CELT results, the researcher decided to choose the participants whose score range was one standard deviation above and below the mean (i.e., mean \pm 1 ). The rationale behind such application was to make sure that the EFL learners of all groups were all at the intermediate level of language proficiency and; therefore, could serve the purpose of the researchers.

\subsubsection{Test of General Vocabulary Knowledge}

Alongside the CELT, a test of general vocabulary knowledge was constructed and used for homogenizing the participants. This test consisted of 40 multiple-choice items and the questions were made based on the vocabulary presented in the intermediate level books of "Interchange 3rd Edition" and "True to Life". The vocabulary test was made 
based on the topics such as jobs, people, human characteristics and feelings, disasters, expressions, prepositions, and animals. The test was piloted among 30 intermediate students who were not the main subjects of this study. All the items were checked with regard to their item facility and item discrimination. The average score of students on the CELT and vocabulary test were used for homogenizing the selected participants.

\subsubsection{Posttest}

A test was designed to assess the participants' awareness of evaluation and potency dimensions of vocabulary knowledge. In this test, the students were given 20 sentences and for each they had to choose adjectives from a list of 20 for the names of people in the given sentences by paying attention to the verb. This test was used at the end of the term as posttest. For preparing this test, 20 adjectives that describe human characteristics and 20 verbs that are used for the interpersonal domain were taken from Carrigon tables of evaluation and potency (2002) which has the classification for positive/negative and potent/non-potent adjectives and verbs. Five verbs and adjectives were potent and positive such as confident, five were potent and negative such as selfish, five were non-potent and positive such as polite, and five were non-potent and negative such as dishonest. All the verbs and adjectives were the ones which are normally used in interpersonal interaction. The names were paired with two proper names to form the sentence such as "John hit Ted". Students had to choose one of the adjectives that they thought would be the best descriptor for each of the nouns in the sentence. The test was scored twice, once to measure the evaluation dimension of students' vocabulary knowledge and once to measure the potency dimension of the vocabulary knowledge.

\subsubsection{Reading Passages}

The fourth instrument was ten reading passages selected for the purpose of presenting the participants with the adjectives and verbs used in interpersonal relationship focusing at their evaluation and potency dimensions. Several passages were selected from the books on the market. The readability of the selected passages was determined based on Fog's readability formula and finally ten passages which had the almost the same readability indices (about 18.90) and were of the average same length-180 words- were chosen to be used for reading materials. One important consideration in selecting the passages was to select texts that would not require culture-specific or discipline-specific background knowledge. It is clear that all the reading passages were authentic and they were geared to the proficiency level of the subjects in the research since they were all extracted from language teaching materials designed for intermediate EFL learners. Furthermore, the participants in both groups read the same set of reading materials.

\subsection{Procedures}

In order to accomplish this research, as mentioned before, 60 male EFL learners aged from 19 to 34 participated in this study. It should be mentioned that no matter how old or educated they were, all participants were intermediate learners studying English at the intermediate level of language proficiency in some of the language schools. Through considering the normal distribution of the subjects' scores on the proficiency test and the test of general vocabulary knowledge, those scores which were one standard deviation above and below the mean were decided to be in the group of subjects. The participants were randomly assigned to two control and experimental groups (30 students each). Next, instructional treatment was given during students' regular time class, and it lasted for ten sessions. Participants in both groups separately attended these ten sessions of instruction in which they were all given reading passages identical in their semantic content. Both of experimental groups and the control group were taught by the same person using different instructional ways specially constructed for each group. As for the students in experimental group (EG), the perceptual salience of the adjectives and verbs in the reading passages was made via a variety of different typographical techniques such as bolding or capitalizing, while this was not the case with control group. The students in control group (CG) simply read the texts and ask for help in case of difficulties. After completing the treatment phase of the study, to determine the potential effect of visual/textual instruction on evaluation and potency dimensions of deep vocabulary knowledge, the students of both groups took part in a test of evaluation and potency dimensions of deep vocabulary knowledge made by the researchers. 


\section{Findings and Discussion}

In order to explore the aforesaid research questions, a number of descriptive and inferential statistical procedures were used. The results obtained through such analysis will be explained and delineated in the following section. For the groups to be comparable and for an experiment like this to be meaningful, the experimental and control group members were expected to indicate no significant differences. In fact, this kind of homogeneity among the participants made it possible for the researchers to compare the groups at the end of the study, and to see whether the intervention yielded different results. In order to meet the above-mentioned requirement, CELT and a test of general vocabulary knowledge were given to both groups. Table 1depicted the descriptive statistics of the participants' mean scores on the CELT and the test of general vocabulary knowledge.

Table 1. Descriptive Statistics for Each Group's Performance on CELT and General Vocabulary Knowledge Test.

\begin{tabular}{|l|l|l|}
\hline & CG & EG \\
\hline Mean & 14.0584 & 13.8000 \\
\hline Std. Deviation & 2.114 & 2.215 \\
\hline Variance & 4.471 & 4.905 \\
\hline Minimum & 12.00 & 12.00 \\
\hline Maximum & 18.00 & 18.00 \\
\hline
\end{tabular}

Table 1 tells us that the means are statistically very close to each other $(13.80 \approx 14.05)$. Therefore, it can be deduced that the learners in the two groups did not differ greatly from one another. That is, the participants' prior knowledge of vocabulary was statistically almost equal. In order to investigate effect of visual/textual input-based instruction on the awareness of evaluation dimension of deep vocabulary knowledge (i.e., the first research question), the mean and standard deviation of the scores by the two groups from the test of awareness of evaluation dimension of vocabulary in the posttest stage of the study were obtained.

Table 2. The Mean and Standard Deviation of the Scores Obtained by the Two Groups from the Test of Awareness of Evaluation Dimension of Vocabulary in the Posttest Stage of the Study

\begin{tabular}{|l|l|l|l|}
\hline & N & Mean & Standard Deviation \\
\hline Experimental Group & 30 & 17.0000 & 2.86267 \\
\hline Control Group & 30 & 10.1522 & 2.18352 \\
\hline
\end{tabular}

Having obtained the scores of subjects in the two groups, an independent t-test was also administered to answer the research question of the study.

Table 3. T-test for Evaluation Dimension of Vocabulary Knowledge

Group Statistics

\begin{tabular}{|l|l|l|l|l|l|}
\hline & GROUP & $\mathrm{N}$ & Mean & Std. Deviation & Std. Error Mean \\
\hline SUM & 1 & 30 & 17.0000 & 2.86267 & 0.776 \\
\hline & 2 & 30 & 10.1522 & 2.18352 & 1.313 \\
\hline
\end{tabular}


Independent Samples Test

\begin{tabular}{|c|c|c|c|c|c|c|c|c|c|}
\hline & \multicolumn{3}{|c|}{$\begin{array}{l}\text { Levene's Test for } \\
\text { Equality of Variances }\end{array}$} & \multicolumn{6}{|c|}{ T-test for Equality of Mean } \\
\hline & \multirow[t]{2}{*}{$\mathrm{F}$} & \multirow[t]{2}{*}{ Sig. } & \multirow[t]{2}{*}{$\mathrm{t}$} & \multirow[t]{2}{*}{ df } & \multirow[t]{2}{*}{$\begin{array}{l}\text { Sig. } \\
\text { (2tailed) }\end{array}$} & \multirow[t]{2}{*}{$\begin{array}{l}\text { Mean } \\
\text { Difference }\end{array}$} & \multirow[t]{2}{*}{$\begin{array}{l}\text { Std. Error } \\
\text { Difference }\end{array}$} & \multicolumn{2}{|c|}{$\begin{array}{l}95 \% \text { Confidence } \\
\text { interval of the } \\
\text { Difference }\end{array}$} \\
\hline & & & & & & & & Lower & Upper \\
\hline $\begin{array}{l}\text { Equal } \\
\text { Variance } \\
\text { Assumed }\end{array}$ & 3.763 & .058 & 4.011 & 28 & .000 & 2.17000 & 0.24081 & 1.6858 & 2.65419 \\
\hline $\begin{array}{l}\text { Equal } \\
\text { Variance } \\
\text { Not Assumed }\end{array}$ & & & 4.011 & 43.218 & .000 & 2.17000 & 0.24081 & 1.6844 & 2.65558 \\
\hline
\end{tabular}

As can be seen, the obtained t value (4.011) is highly significant. (i.e., the significance level is .000 which is well below 0.01 or even 0.05 ). This suggests that the difference between the means of the experimental and control group is not due to chance alone. The higher mean of the participants in the experimental group gives strong support to the conclusion that the treatment given to the experimental group has been more effective in their evaluation dimension of vocabulary knowledge than that of the control group. Therefore, one can conclude that visual/textual enhancement has been effective in increasing the learners' awareness of evaluation dimension of deep vocabulary knowledge. In order to examine the second research question, descriptive statistics along with the independent t-test are given in table 4 and 5 .

Table 4. Mean and Standard Deviation of the Scores Obtained by the Two Groups from the Test of Awareness of Potency Dimension of Vocabulary in the Posttest Stage of the Study

\begin{tabular}{|l|l|l|l|}
\hline & N & Mean & Standard Deviation \\
\hline Experimental Group & 30 & 18.3333 & 6.2354 \\
\hline Control Group & 30 & 6.1667 & 3.0485 \\
\hline
\end{tabular}

Having obtained the scores of subjects in two groups, an independent t-test was administered to answer the second research question of the study i.e., "Does visually/textually enhanced input have any statistically significant effect on Iranian intermediate EFL learners' awareness of potency dimension of vocabulary?".

Table 5. T-test for Potency Dimension of Vocabulary Knowledge

Group Statistics

\begin{tabular}{|l|l|l|l|l|l|}
\hline & GROUP & N & Mean & $\begin{array}{l}\text { Std. } \\
\text { Deviation }\end{array}$ & $\begin{array}{l}\text { Std. Error } \\
\text { Mean }\end{array}$ \\
\hline SUM & 1 & 30 & 18.3333 & 6.2354 & 1.0452 \\
\hline & 2 & 30 & 6.1667 & 3.0485 & 0.8534 \\
\hline
\end{tabular}


Independent Samples Test

\begin{tabular}{|c|c|c|c|c|c|c|c|c|c|}
\hline & \multicolumn{3}{|c|}{$\begin{array}{l}\text { Levene's Test for } \\
\text { Equality of Variance }\end{array}$} & \multicolumn{6}{|c|}{ t-test for Equality of Mean } \\
\hline & \multirow[t]{2}{*}{$\mathrm{F}$} & \multirow[t]{2}{*}{ Sig. } & \multirow[t]{2}{*}{$\mathrm{t}$} & \multirow[t]{2}{*}{ df } & \multirow[t]{2}{*}{$\begin{array}{l}\text { Sig. } \\
\text { (2tailed) }\end{array}$} & \multirow[t]{2}{*}{$\begin{array}{l}\text { Mean } \\
\text { Difference }\end{array}$} & \multirow[t]{2}{*}{$\begin{array}{l}\text { Std. Error } \\
\text { Difference }\end{array}$} & \multicolumn{2}{|c|}{$\begin{array}{lr}95 \% & \text { Confidence } \\
\text { interval of the } \\
\text { Difference }\end{array}$} \\
\hline & & & & & & & & Lower & Upper \\
\hline $\begin{array}{l}\text { Equal } \\
\text { Variance } \\
\text { Assumed }\end{array}$ & 9.958 & .004 & 8.823 & 28 & .000 & 17.3333 & 1.96461 & 13.30902 & 21.35765 \\
\hline $\begin{array}{l}\text { Equal } \\
\text { Variance } \\
\text { Not Assumed }\end{array}$ & & & 8.823 & 23.712 & .000 & 17.3333 & 1.96461 & 13.27958 & 21.39069 \\
\hline
\end{tabular}

As the table indicates, the obtained t value ( 8.823 is highly significant. (i.e., the significance level is 0.000 which is well below 0.01 or even 0.05 ). This suggests that the difference between the means of the experimental and control group is not due to chance alone. The higher mean of the participants in the experimental group gives strong support to the conclusion that the treatment given to the experimental group has been more effective than that of the control group in their potency dimension of vocabulary knowledge. Therefore, one can conclude that input-based instruction has been effective in increasing the learners' awareness of potency dimension of deep vocabulary knowledge.

\section{Concluding Remarks}

\subsection{Discussion}

According to the findings obtained in the light of running different statistical tests, it was deduced the participants in the experimental group, who were taught via input-based instruction, appeared to have benefited from this implicit focus on form method of formal instruction. This was based on the assumption that using typographical cues to enhance the awareness of affective dimensions of deep vocabulary knowledge would increase their perceptual salience, which in turn would push participants to notice the enhanced words and select them as intake, leading to better performance on the posttest.

The most convincing explanation for such a finding may come from the works of Sharwood Smith $(1991,1993$, 1994), who is the originator of input enhancement. Sharwood Smith (1994) contends that "the most obvious way to try to affect the subconscious processes beneficially is by making relevant evidence in the input especially salient" ( $p .178)$. Therefore, it can be claimed that the findings of this study lend support to Sharwood Smith's speculations (1994) that visually/textually enhanced input has a positive impact on the rate and accuracy of $L 2$ acquisition. Besides, the results of the research question provide further empirical support for (Doughty, 1988; Shook, 1994; Williams, 1999).

\subsection{Conclusions}

The outcome of the posttest data analysis clarified that the subjects in the experimental group significantly outperformed the subjects in the control group. Therefore, the obvious conclusion is that the devised treatment i.e., application of inputbased treatment has helped the participants in the experimental group to perform better than the control group in tests. Here we can conclude that if our students are exposed to visually/textually enhanced input, they will have better knowledge of affective dimensions of deep vocabulary knowledge. Actually, the results of this research proposed some evidence in favor of the facilitative role of implicit instruction in second language acquisition. Such results are consistent with a lot of researches aimed at proving that implicit instruction is advantageous (Long, 1983; Norris \& Ortega, 2000). 


\subsection{Pedagogical Implication}

Teachers can make use of visual/textual enhancement as a teaching device in their classes. Using visually /textually enhanced input may be beneficial in teaching evaluation and potency dimensions of deep vocabulary knowledge because they can create new situation for the students and learning would be more interesting. When students receive vocabulary instruction through typographical enhancement, they can increase deeper knowledge of vocabulary which helps to use the vocabularies in appropriate situation.

Teachers can utilize proper type of input to improve the learners' deep vocabulary knowledge. Exposing the students to input-based treatment will enhance learner's appropriate use of vocabularies. It can be pointed out that in this way learning vocabularies can be more interesting and more authentic to learners. Enhancement can create more preparatory condition to achieve deeper knowledge of vocabularies.

\section{References}

Alanen, R. (1995). Input enhancement and rule presentation in second language acquisition. In R. Schmidt (Ed.), Attention and awareness in foreign language learning. Honolulu: University of Hawai'i Press.

Doughty, C. (1988). The effect of instruction on the acquisition of relativization in English as a second language, Ph.D. Thesis. University of Pennsylvania, USA.

Doughty, C. (1991). Second language instruction does make a difference. Studies in Second Language Acquisition, 13, 341-469.

Ellis, N. (1999). Cognitive approaches to SLA. Annual Review of Applied Linguistics, 19, 22-42.

Gass, S. (1997). Input, interaction and the second language learner. Mahwah, NJ: Lawrence Erlbaum Associates.

Heise, D. (2002). Understanding social interaction with affect control theory. In J. Berger \& M. Zelditch (Eds.), New direction in contemporary sociologicaltheory (pp.17-40). Lanham, MD: Rowman \& Littlefield.

Laufer, B. (1997). The lexical plight in second language reading. Cambridge: Cambridge University Press.

Leow, R. (1993). To simplify or not to simplify: A look at intake. Studies in Second Language Acquisition, 15, 333-55.

Long, M. H. (1983). Does instruction make a difference? TESOL Quarterly, 17, 359-382.

McLaughlin, B. (1987). Theories of second language learning. London: Edward Arnold.

Norris, J., \& Ortega, L. (2000). Effectiveness of L2 instruction: A research synthesis and quantitative meta-analysis. Language Learning, 50(3), 417-582.

Osgood, C., May, C., \& Miron, M. (1975). Cross-cultural universals of affectivemeaning. Urbana, IL: University of Illinois Press.

River, W. M. (1981). Foreign language skills. Chicago: University of Chicago Press

Robinson, P. (1996). Learning simple and complex language rules under implicit, incidental, rule search, and instructed conditions. Studies in Second Language Acquisition, 18, 27-76.

Robinson, P. (1997). Generalizability and automaticity of second language learning under implicit, incidental, enhanced, and instructed conditions. Studies in Second Language Acquisition, 19, 323-247.

Schmidt, R. (1990). The role of consciousness in second language learning. Applied Linguistics, 11(2), 17-46.

Schmidt, R. (1993). Awareness and second language acquisition. Annual Review of Applied Linguistics, 13, 26-226.

Schmidt, R. (1995). Attention and awareness in foreign language learning. Honolulu, HI: University of Hawai'i Press.

Sharwood Smith, M. (1991). Speaking to many minds: On the relevance of different types of language information for the L2 learner. Second Language Research, 7, 118-132.

Sharwood Smith, M. (1993). Input enhancement in instructed SLA. Studies in Second Language Acquisition, 15, 165-179.

Sharwood Smith, M. (1994). Second language learning: Theoretical foundations. New York, NY: Longman.

Shook, D. (1994). FL/L2 reading, grammatical information, and input-to-intake phenomenon. Applied Language Learning, 5, 5793.

Tomasello, M. (1998). Introduction to the new psychology of language: Cognitive and functional approaches to language structure. Mahwah, NJ: Lawrence Erlbaum Associates.

White, J. (1998). Getting the learners' attention: A typographical enhanced study. In C. Doughty \& J. Williams (Eds.), Focus-onform in classroom second language acquisition. New York: Cambridge University Press.

Williams, J. (1999). Memory, attention, and inductive learning. Studies in Second Language Acquisition, 21, 1-48. 